\title{
Physico-chemical Characterization Of Various Powdered Milk Samples Available In Butwal Sub-Metropolitan City, Rupandehi, Nepal
}

\author{
Deepak Kumar Shrestha*
}

\begin{abstract}
Milk is nearly complete food and contains all the essential components in nearly balanced form. In the present study four different brands of powdered milk samples- Nestle, Amulya, Milkyday and Patanjali commercially available in local market of Butwal city, Rupandehi were collected and analyzed. These powdered milk samples were analyzed to know the physico-chemical characteristics including moisture, $p H$, viscosity and electrical conductivity. It was found that all measured physical and chemical parameters of commercially available milk powder in Butwal city were found as per recommended standard as compared with reported nutritional quality of milk from various countries. The main objective of the study is to determine some of the physico-chemical properties of different powdered milk samples available in Butwal city and provide nutritional benefits for health. All these tests were carried out in BMC college laboratory. The value of $p H$ ranged from 6.65 to 6.77 , percentage of moisture content from $3.9 \%$ to $4.5 \%$, where Patanjali powder milk had highest $\mathrm{pH}$ and highest moisture content. Similarly, the viscosity ranged from $0.96 c P$ to $1.8 c P$ and the electrical conductivity ranged from $6.54 \mathrm{mS}$ to $9.6 \mathrm{mS}$ among different powder milk brands. Milky day had highest viscosity and Patanjali had highest conductivity. These parameters were determined and data were analyzed from period of 15 July 2019 to 30 July 2019.
\end{abstract}

Keywords: Physicochemical characteristics, powdered milk, milk analysis

\section{INTRODUCTION}

Milk is an important sources of all basic nutrients required for mammals including human beings. Milk is a complex colloidal solution (emulsion) containing fat globules, casein micelle and whey proteins in aqueous solution of lactose, minerals and few other minor compounds. Milk is the characteristics secretion of mammary glands of all mammals. . In 2011 , FAO estimates $85 \%$ of all milk worldwide is produced from cow, about $11 \%$ by buffaloes, $2 \%$ by goats, $1.4 \%$ by sheep and $0.2 \%$ by camels. So cow's milk dominates commercial production worldwide.

Fresh milk is considered as the complete food (diet) because it contains all the essential nutrients as lactose, fat, protein, minerals and vitamins in balanced ratio rather than other food.(Hossain et al., 2013). According to (Byron et al., 1974) the average composition of fresh milk is water $87.20 \%$, dry matter $12.80 \%$ (fat $3.70 \%$, Protein $3.50 \%$, Lactose $4.90 \%$ and Ash $0.70 \%$ ).

Powdered milk or dried milk is a dairy product obtained by the removal of water (or fat) from whole milk used in manufacturing ice cream, infant foods, bakery goods, confections and sausages. Ninety percent of the water in the milk is removed in the evaporator and only ten percent in the spray dryer (Robinson et.al., 1994). The inappropriate storage conditions such as high relative humidity and high ambient temperature can significantly degrade the nutritive value of powdered milk. One purpose of drying milk is to preserve it. It has a much longer keeping quality

*Lecturer, Department of Chemistry, Butwal Multiple Campus, Butwal, shresthadeepak854@gmail.com 
due to its low moisture content, easy distribution is possible with unfavorable conditions. Usually fat percent of skimmed milk powder minimum $1.5 \%$ and maximum $2.5 \%$. For all types of powder milk water content ranges from 3-5\% (Edgar Spreer et al., 2017). The $\mathrm{pH}$ in within range of 6.6 to 6.8 , moisture within range of 3.37 to $4.4(\mathrm{~g} / 100 \mathrm{~g})$ for whole milk powder of different brands available in Mymensingh town Bangladesh (Kajal et al., 2012). According to ADMI (1971) the moisture content of whole milk powder in within range of $2-5 \%$. The conductivity within range of 6.55 to $10.8 \mathrm{mS}$ and viscosity within range of 1.38 to $1.52 \mathrm{cP}$ for fresh milk of different mammals (buffalo, cow and goat) available in Pakistan (Imran et al., 2008). Powdered milk is advantages for its concentrated source of many essential nutrients (Hall et al., 1966). Powdered milk is also a common item in UN food aid supplies, fallout shelters, warehouses, and wherever fresh milk is not a viable option.

The present study was designed to evaluate some physicochemical parameters, to give baseline information about the effects and health hazards caused by poor quality milk powder etc. Some experimental errors, observational errors and calculation errors might occurred during experiment.

\section{MATERIALS AND METHODS Collection of the Sample}

The present experiment was conducted in Chemistry lab of BMC. To perform the experiment, four commercial brands of milk powder Viz, Nestle, Amulya, Patanjali and Milky day were selected from local market of Butwal city which delivered whole milk powdered in poly packet. They were kept in dry place until analysis.

\section{Physical Analysis}

The physical parameters were determined shortly after they were brought to the laboratory. Conductivity was determined according to AOAC 2000 's methods and viscosity by Rehman Salaria (2005).

\section{Chemical analysis}

pH was determined by $\mathrm{pH}$ meter (HI 98107, HANNA Instruments, Romania). Moisture content was determined by the difference between known weight of powder milk and the determined wt. of total solid after evaporation by AOAC 2000's method.

\section{Statistical analysis}

The primary data was collected after the experimentation and observation in the lab. The statistical analysis was done as per Steel and Torrie (1980), using Completely Randomized Design (CRD). The data was analyzed using appropriate statistical tools such as bar diagram, line graph to find out the statistical differences within the quality of four types of packaged powdered milk.

\section{Chemicals and Reagents used}

$0.1 \mathrm{~N} \mathrm{KCl}$ solution, Acetone, Ethanol, Distilled water, chromic acid

\section{Apparatus used}

Measuring cylinder, Test-tube, Pipette, Beaker of different size, Funnel, Filter paper, Conductivity meter, Conical flask, Water bath, air Oven, Alumilium dish Spatula, Wire gauze, Desiccators, Tripod stand, pH meter, digital balance Ostwald' Viscometer, etc.

\section{Determination of physico-chemical parameters of powder milk \\ Determination of $\mathrm{pH}$}

The $\mathrm{pH}$ is a numeric scale used to specify whether the aqueous solution is acidic or alkaline. Solutions with $\mathrm{pH}$ less than 7.0 are acidic and solutions with $\mathrm{pH}$ greater than 7.0 are basic. Milk is slightly acidic close to neutral $\mathrm{pH}$. The exact value depends on how the powder milk was produced, processing done to it, and how long it was packaged or opened.

The $\mathrm{pH}$ of milk samples were determined by using digital pH meter (HI 98107, HANNA Instruments, Romania). For $400 \mathrm{ml}$ of reconstitution milk $50 \mathrm{~g}$ of well mixed sample of each dried whole milk with distilled water was taken in separate sterile beakers at temperature $28^{\circ} \mathrm{C}$ and $\mathrm{pH}$ was measured (AOAC, 2000).

\section{Determination of Moisture Content}

Measuring the moisture content in powdered milk is an important quality control step. Moisture content was determined according to the modified method of AOAC (2000). $5 \mathrm{gm}$ of powder 
sample was placed in a clean dried flat bottomed aluminium dish. The weight of sample and dish were recorded $\left(\mathrm{W}_{0}\right)$, and the dishes were heated on air oven at $100^{\circ} \mathrm{C}$ for 3 hours. The dishes were transferred to desiccators to cool and weighed $\left(\mathrm{W}_{1}\right)$. Heating, cooling and weighing were repeated several times until the difference between successive weights was $<1 \mathrm{mg}$. The moisture was calculated from the following equation:

Moisture content $(\%)=\left(\mathrm{W}_{1} / \mathrm{W}_{0}\right) \times 100$

Where, $\mathrm{W}_{1}=$ weight of sample after drying

$\mathrm{W}_{0}=$ weight of sample before drying

\section{Determination of Viscosity}

Viscosity is a measure of a fluid's resistance to flow.Viscosity was determined using the procedure followed by Rehman and Salaria (2005). Ostwald Viscometer was used to determine the viscosity of different milk powder samples. $1 \%$ milk solution was prepared in separate sterile beakers by using distilled water and kept for 2-3 hours for complete dissolution of sample. Lower bulb of viscometer was filled with sample and upper bulb was filled by pipette upto the mark. Then the sample was let to flow freely from upper bulb and at the same time, the rate was detected by stop watch. The process was made thrice to find the accurate value of rate of flow. Standard distilled water was used to calculate the relative viscosity of water sample. Total rate of flow of sample was calculated by following method:

Rate of flow of time $\mathrm{T}=$ Sum of time taken/No. of Time $\left(\mathrm{T}_{1}+\mathrm{T}_{2}+\mathrm{T}_{3}\right) / 3$

Relative Viscosity $\eta_{1}=d_{1} T_{1} \eta_{2} / d_{2} T_{2}$

$\mathrm{d}_{1}=$ density of sample, $\mathrm{d}_{2}=$ density of standard water $\eta_{1}=$ coefficient of viscosity of sample, $\eta_{2}=$ viscosity of standard water.

$\mathrm{T}_{1}=$ time flow for milk sample, $\mathrm{T}_{2}=$ time flow for distilled water

$\eta_{2}=0.890$ at STP

Hence density of water for $\mathrm{d}_{1} \& \mathrm{~d}_{2}=$ constant $=1.0 \mathrm{gm} / \mathrm{cm}$ Measurement of Conductivity

Conductivity of an electrolyte solution is a measure of its ability to conduct electricity. The SI unit of electrical conductivity is Siemens per meter $(\mathrm{S} / \mathrm{m})$ or simply milliSimens $(\mathrm{mS})$.

For the measurement of conductivity, conductivity meter (CM-611-E-M.s Electronics) was used throughout the sampling period. $10 \mathrm{gm}$ of milk powder was dissolved in $100 \mathrm{ml}$ of distilled water in separate sterile beakers and refluxed. Conductivity meter was first dipped in $\mathrm{KCl}$ solution $(0.1 \mathrm{~N})$ for 1 hour and washed with distilled water at least 2-3 times. Then conductivity meter was dipped in milk sample and conductivity of milk powder was measured directly.

\section{RESULTS AND DISCUSSIONS}

The four different brands of powdered milk samples were analyzed by different standard procedures as mentioned above. The methods of calculation for each parameter were mentioned above and the result obtained and parameters are tabulated below. The value of $\mathrm{pH}$ ranged from 6.65 to 6.77 , percentage of moisture content ranged from $3.9 \%$ to $4.5 \%$, among where Patanjali powder milk had highest $\mathrm{pH}$ and highest moisture content. Similarly, the viscosity ranged from $0.96 \mathrm{cP}$ to $1.8 \mathrm{cP}$ and the electrical conductivity from $6.54 \mathrm{mS}$ to $9.6 \mathrm{mS}$ among the different brands of powder milk. Milky day had highest viscosity and Patanjali had highest conductivity as given in the table-1.

Table-1: Physico-chemical parameters of different powdered milk samples available in Butwal Submetropolitan city

\begin{tabular}{|l|c|c|c|c|}
\hline $\begin{array}{c}\text { Physico-chemical } \\
\text { parameters }\end{array}$ & Nestle & $\begin{array}{c}\text { Amu- } \\
\text { lya }\end{array}$ & $\begin{array}{c}\text { Patan- } \\
\text { jali }\end{array}$ & $\begin{array}{c}\text { Milky } \\
\text { Day }\end{array}$ \\
\hline $\mathrm{pH}$ & 6.70 & 6.68 & 6.77 & 6.65 \\
\hline Moisture (\%) & 4.0 & 4.3 & 4.5 & 3.9 \\
\hline Viscosity (cP) & 0.96 & 1.3 & 0.99 & 1.8 \\
\hline Conductivity (mS) & 6.54 & 7.68 & 9.6 & 6.8 \\
\hline
\end{tabular}

\section{Variation of $\mathbf{p H}$}

Different compounds in milk powder act as buffering agents, so that mixing it to other chemical brings their $\mathrm{pH}$ closer to neutral. The $\mathrm{pH}$ of milk changes over time.

All the four samples were found to be slightly acidic or close to neutral in nature having the $\mathrm{pH}$ value 
ranged from 6.0 to 6.8 . The $\mathrm{pH}$ value of all the samples is tabulated in Table-1 and is graphically represented below in fig. 1. The $\mathrm{pH}$ range found in current study was comparable with the finding in previous investigation in packed powder milk. 6.5 to 6.7 (Jenness and Patton, 1959). Among four samples, Milky Day had the lowest pH 6.65 and the highest was found to be of Patanjali 6.77.

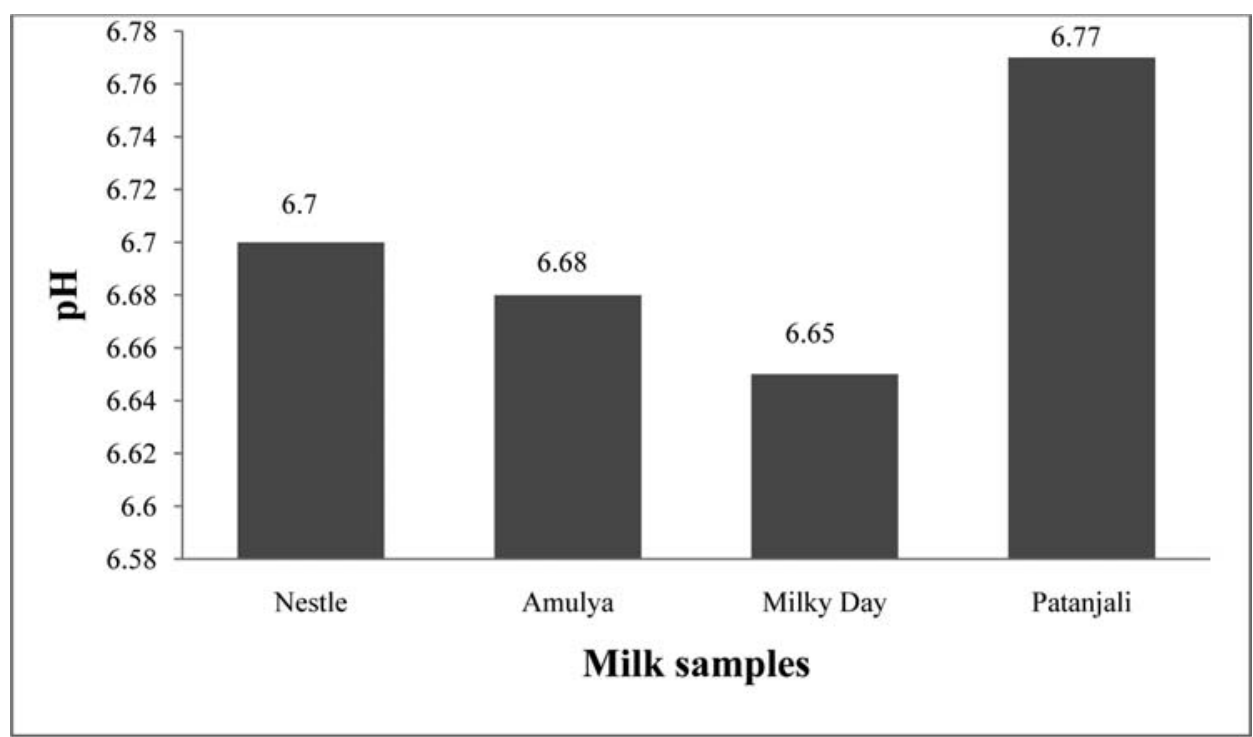

Fig.1: Variations of $\mathrm{pH}$ of different milk powder samples

\section{Variation of Moisture Content}

Moisture content is the quantity of water contained in the material. In the present study, the range of moisture content was from $3.7 \%$ to $5 \%$ as given in the table-1. Among four samples, Milky Day had the lowest moisture content $(3.9 \%)$ followed by
Nestle (4.0\%), Amulya (4.3\%) and Patanjali (4.5\%). All these values were closer to the earlier finding from $2 \%$ to $5 \%$ (ADMI, 1971). The results are shown in the table-1 for the further discussion and graphically represented below:

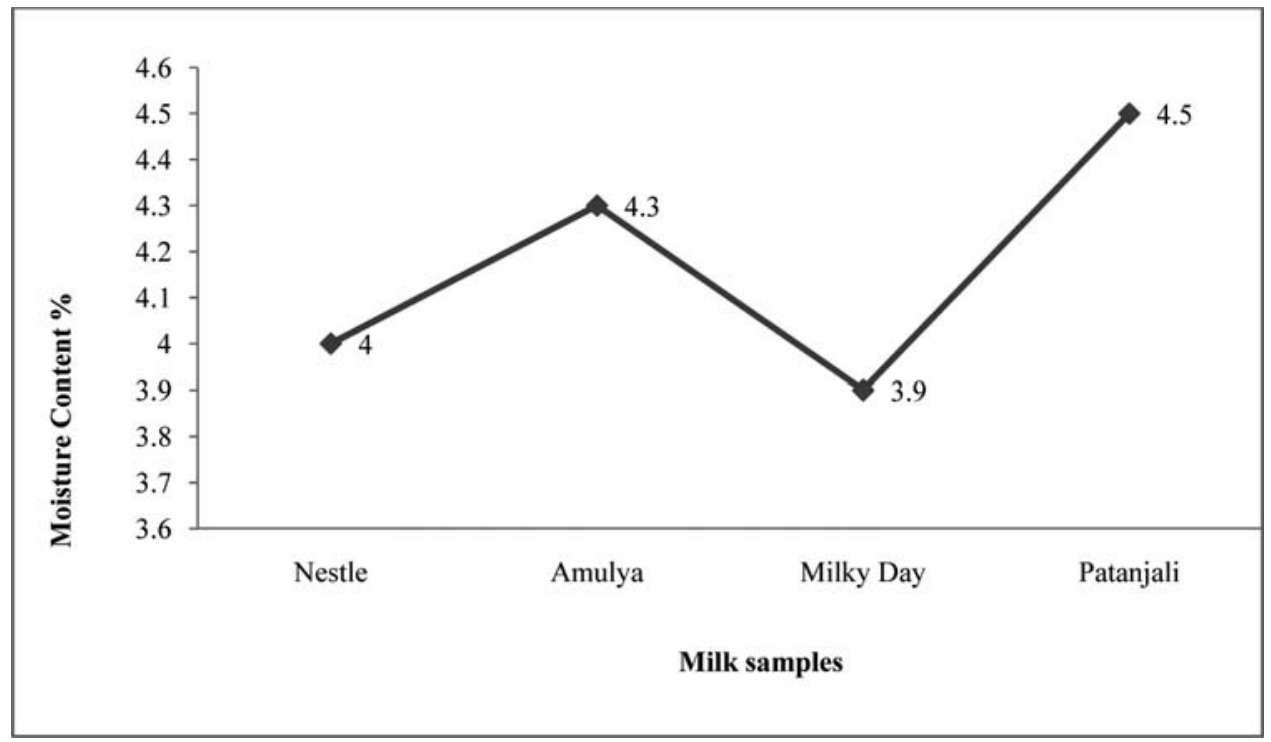

Fig 2: Variation of moisture content of different powdered milk samples 


\section{Variation of Viscosity}

The results shown in this study showed that the range of viscosity was from $0.96 \mathrm{cP}$ to $1.8 \mathrm{cP}$.
Nestle had lowest viscocity $0.96 \mathrm{Cp}$ followed by milky day $0.99 \mathrm{Cp}$ and Amulya $1.3 \mathrm{cP}$ and the highest viscocity was of patanjali $1.8 \mathrm{cP}$.

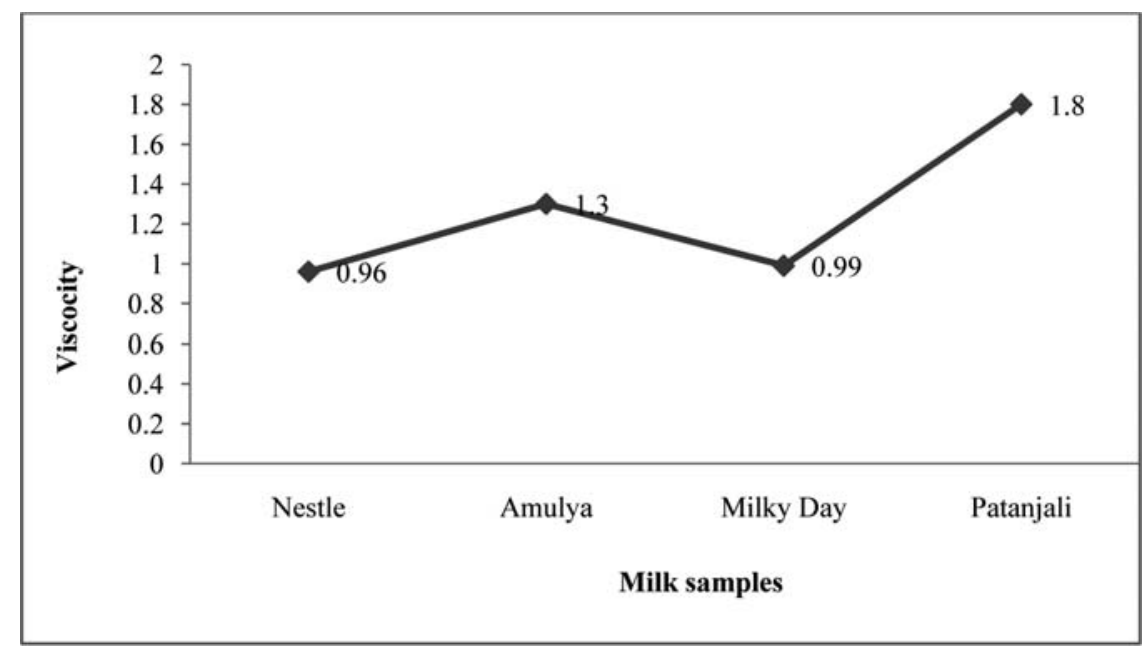

Fig 3: Variation of viscocity of different milk powder

\section{Variation of Conductivity}

The results obtained in this study showed that Patanjali had the highest electrical conductivity 9.6 $\mathrm{mS}$ followed by Amulya $7.68 \mathrm{mS}$, then Milky Day 6.8
$\mathrm{mS}$ and Nestle had the lowest EC of $6.54 \mathrm{mS}$ respectively measured at $30^{\circ} \mathrm{C}$ in chemistry lab of BMC. The results obtained in this study are graphically represented below.

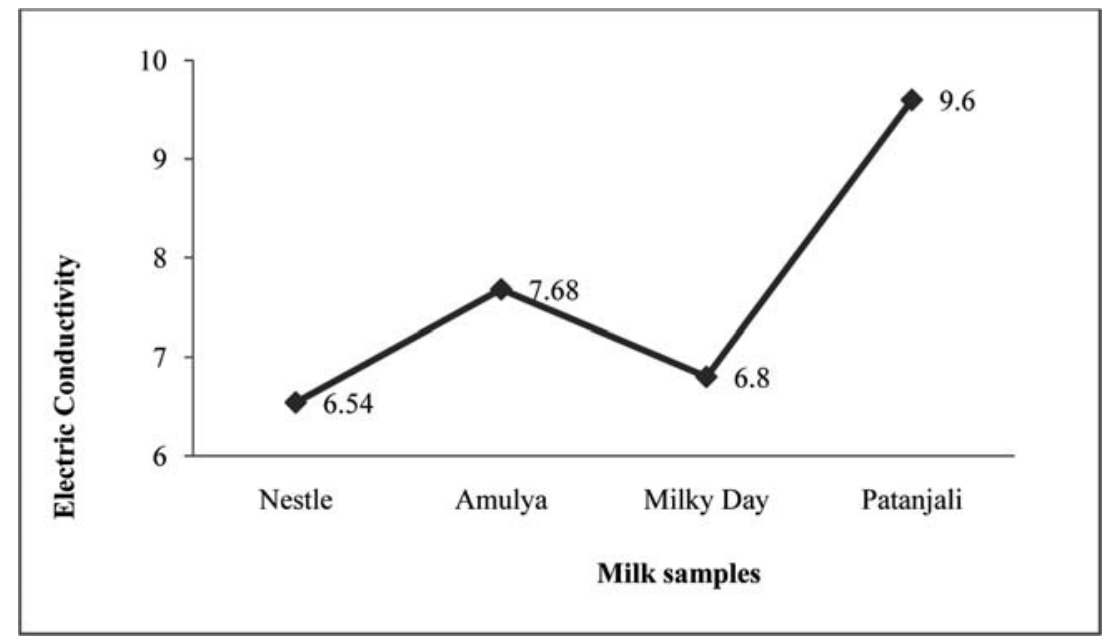

Fig 4: Variation of electric conductivity of different milk powder

\section{Conclusion}

In the present study, preliminary investigations were carried out to ascertain the physicochemical characteristics and nutritional quality of different powdered milk samples marked in Butwal city. The result showed that parameters of the tested powdered milk samples within the recommended levels. These findings may be helpful for the concerned peoples and governmental parties to monitor the quality of milk products in the market of Butwal city. 


\section{Acknowledgement}

The author would like to express thanks to RMC of Butwal Multiple Campus and especially Prof. Dr. Ananta Panthi and HOD, Dr. Krishna Sharma, Department of Chemistry of BMC.

\section{References}

American Dry Milk Institute (ADMI) Inc. (1971). Standards for Grade of Dry Milk Including Methods of Analysis, Bulletin 916.

AOAC (Association of Official Analytical Chemists), (2000).Official Methods of Analysis International, 17thEd. AOAC, Washington, DC.

Bhatia, A; Bhojak, N. and Gakkhar, N; (June 2015). Comparative Study on Physicochemical Properties of Various Milk Samples. International Journal of Recent Scientific Research Vol.6, (6) pp: 4436-4439.

BSTI (Bangladesh Standards and Testing Institution) Mann Bhaban, Dhaka, Bangladesh-1208

Byron, H. W., Amold, H.J. and Jhon, A.A. (1974). Fundamentals of Dairy Chemistry. The Avi Publishing Company Inc. 2nd Ed. pp. 2-8.

Edgar Spreer, Milk and Dairy product Technology. Routledge, (2017).

FAO/WHO. (1973). Code of principles concerning milk and milk products ( $7 \mathrm{~h}$ Ed.) Standard for whole milk powder, partly skimmed milk powder and skimmed milk powder. No. AS. FAO/WHO.

Hall, C.W. and Hendrick, T.I. (1966) "Drying of milk and milk products"(2nd ed.).The Avi publishing comp.Westport (Conn.).

Hassan, S.S.(2005). Quality Assurance of Various Dairy Products. Pakistan, Department of Chemistry, University of Peshawar; (M.Sc. Thesis)

Hossain, M. Bellal, and Sima Rani Dev. (2013) "Physiochemical characteristics of various raw milk samples in a selected dairy plant of Bangladesh. "International Journal of Engineering 1.3; 2305-8269.

Imran, M., Khan, H., Hassan, S., S. and Khan, R. (2008). Institute of Chemical Sciences, University of Peshawer, Peshawer- 25120; Pakistan. "Physicochemical characteristics of various milk samples available in Pakistan". Copyright (C) 2008 Journal of Zhejiang University Science B 2008 Jul, 9(7): 546-551.

Milk Industry Foundation. Laboratory Manual (1959): Methods of Analysis of Milk and its products.

M.F.I. Kajal, A. Wadud, M.N. Islam and P.K. Sarma. Department of daily Science, Bangladesh Agricultural University Research System, Bangladesh Agricultural University, Mymensingh-2202, Bangladesh. E-mail:kajalfi2012@gmail.com.

Minard, R.. (1990) (Penn State Univ. Department of Chemistry. USA) Isolation of Casein, Lactose and Albumin from Milk,

Webb, Q; Dan W; Bin D; Zaijun L; and Yanqlang H.(2006). Journal of Food Composition and Analysis, 19(1), pp:76-82. 